\title{
Measurement Of Gross Alpha And Beta Radioacivity In Ground Water From Some Bore Holes And Wells In Kaduna North Local Government Area Of Kaduna State.
}

\author{
Abdu Ibrahim ${ }^{1,}$ Dahiru Dahuwa ${ }^{2,}$ Ibrahim Bello ${ }^{3}$ \\ (Physics Department College of Education Azare, Bauchi State. Nigeria) ${ }^{1,2,3}$
}

\begin{abstract}
Twenty samples of borehole and well water were taken from the Kaduna North Local Government Area of Kaduna,Kaduna state, Nigeria, in two litre plastic jerrycans.Two drops of concentrated nitric acid were to each container in order to preserve the samples. The total dissolved solids (TDS) were determined for the water samples. An aliquot of each sample was evaporatated to dryness, and transferred to a planchet. Based on the total dissolved solids (TDS) of the sample, the residue was counted for gross alpha and beta activity using the proportional counter. The results show that the counter has low background and good plateau, which were all reproducible: and for the counting modes, results show that alpha and beta activity concentrations range from $(0.69 \pm 1.52) \times 10^{-3}$ to $(41.2 \pm 25.7) \times 10^{-3} \mathrm{~Bq} / \mathrm{L}$ : and from $(286 \pm 77.1) \times 10^{-3}$ to $(9506 \pm 104) \times 10^{-3} \mathrm{~Bq} / \mathrm{L}$ respectively.The overall show that that the alpha activity in the study area is far below the practical screening level of radio activity in drinking water of $0.5 B q / L$ for alpha, as rcommended by CEC-FAO AND WHO.However, a full sixty percent of the samples show beta activity levels above the 1Bq/Las rcommended by CEC-FAO AND WHO.Radionuclide specific tests therefore indicated.
\end{abstract}

\section{Introduction}

Water is a necessityto man and his environment; it existed long before man came into existence. Water forms greater percentage of human and animal blood and tissue. Water for human consumption should be free from chemical, microbiological and radiological contamination. In Kaduna North local government area,Kaduna State,people rely mostly on the ground sources comprising hand wells and boreholes (deep and shallow). While the infrastructure for tap waterexists, most of the time the water does not flow; most of the populace rely heavily on untreated ground water sources as their sources of drinking water.It becomes necessary therefore, to investigate the radiological content of drinking water in the environment. Radioactivity in ground water was formerly limited to natural sources such as radon, radium, or uranium, but release from fertilizers, agrochemicals, medical and research facilities have added the dimension of man-made radioactivity finding its way into drinking sources. This is to say that radioactivity in drinking water comes from two sources: naturally occurring and artificially induced. These contaminations may pose a potential health hazard, and therefore the need for investigation is very important. Water quality is an important parameter of environmental studies (Karahanetal., 2000).Natural water contains both $\alpha$-(e.g., $\mathrm{U}^{238},{ }^{230} \mathrm{Th},{ }^{226} \mathrm{Ra},{ }^{210} \mathrm{Po}$ ) and $\beta$ - (e.g.,. $\mathrm{K}^{40}$ ) emitters in widely varying concentrations which are responsible for a generally small fraction of the total dose received from natural and artificial radioactivity (UNSCEAR, 1993). Gross alpha and gross beta radioactivity measurements are of particular interest for routine monitoring purposes.

\subsection{Statement of research problem}

Kaduna North, is one of the local government areas of Kaduna,Kaduna state, Nigeria, with a population of around 357,694 inhabitants according to NPC data of 2006 census, and its geological studies indicte that it is rich in granite deposits. Thomas etal(1987),reported that majority of areas with high radon concentrations are those areas underlain by granite rocks that contain higher levels of radon precursors. In Nigeria, Kaduna North local government area in particular, there is as yet no established data on gross alpha and beta concentrations in drinking water sources, despite the fact that most of the inhabitants of the country, especially those in the rural areas,depend solely on ground water and surface water sources for drinking,household activities, agricultural purposes; and it may be possible that the water they use contain high concentrations of gross alpha and beta emitters.

\section{Aim}

The aim of this research is to evaluate the gross alpha and beta activity levels in water from wells in Kaduna North local government area of Kaduna State.

\section{Objectives}

- To evaluate the gross alpha and beta radioactivity in water from wells and boreholes in Kaduna North local government area,Kaduna, of Kaduna state; 
- To identify possible areas of elevated activity;

- To establish the distribution pattern of radioactivity measured in the area, so as to assess the ground water for drinking.

\subsection{Justification}

Radiation is harzadous to human health.Alpha and beta particles deposit their energy at short distances which cause damage in organs when taken into the body,forexample, by drinking water with dissolved radionuclides.It is important that drinking water be characterized with respect to radionuclidescontent.However,nuclides characterization is costly,thereforegross alpha and beta counting becomes a necessary preliminary test as stipulated by the WHO guideline for water quality determination.Radionuclide specific tests will become necessary only if the results of the preliminary tests exceed a recommended value.Therefore,establishing a gross alpha and beta counting system,would not only contribute to the health of the populace,but is also economical in that it offers a more cost effective means of screening the drinking water for hazardous radionuclides.

\section{Radioactvity}

The naturally occurring radioactive materials (NORMs) in the earth's crust comprise Uranium, Thorium, Radium, with their radon-gas progeny and potassium-40. These materials seep into the ground water, introducing radioactivity into water bodies. For any element, there are a limited number of neutrons within the nucleus for it to remain stable. Any deviation from this number will result in an unstable atom. An unstable atom can become more stable by emitting energy/particles.The emitted particles are alpha particles, beta particles or positrons; gamma radiationsusually accompany alpha or beta particle emissions. (Cember, 1996). The exact mode of radioactive transformation depends on two factors: (i) the type of instability-that is, whether the neutron to proton ratio is too high or too low; (ii) The mass-energy relationship between the parent nucleus and the emitted particle.

\subsection{Radioactive decay law}

The instability of a nucleus describes a statistical phenomena, hence the associated transformation process is probabilistic (random in nature). The random behaviour of a particular radioactive sample is expressed in the radioactive decay law, which states that if $\mathrm{N}$ represents the number of atoms of a radionuclide in a given sample at a time $\mathrm{t}$, then the change in the number of nuclides, $\mathrm{dN}$, during a time interval $\mathrm{dt}$ is proportional to N.Thus,

$$
\frac{\mathrm{dN}}{\mathrm{dt}}=-\lambda \mathrm{N}
$$

Where $\lambda$ is called the decay or transformation constant. The negative sign shows that $\mathrm{N}$ decreases as time, t,increases.Therefore,

$\mathrm{N}(2.2)$

$$
\underline{\mathrm{dN}}=-\lambda \mathrm{dt}
$$

Solving equation 2.2 by integration and taking natural logs, will result in the equation $\mathrm{N}=\mathrm{N}_{\mathrm{o}} \mathrm{e}^{-\lambda t}(2.3)$

Where $\mathrm{N}_{0}$ is the number of atoms of the radionuclides at time $\mathrm{t}=0$ Equation 2.3 is the radioactive decay law.

\subsection{Radionuclides in drinking water}

The occurrence of dissolvedradio nuclides, such as ${ }^{238} \mathrm{U},{ }^{226} \mathrm{Ra}$ and ${ }^{222} \mathrm{Rn}$, in water, pose serious health hazards. Studies have shown that there is no safe radiation dose; accumulation of these radionuclides in the body overtime may lead to several types of cancers, and extremely high doses can cause death. Radium and uranium are known to be alphaemitters, and when ingested into the body pose a variety of health problems (Cohen,1987). Radon, for instance, has similar chemical properties with calcium, thus it accumulates in bone tissue. Inducement of bone cancer appears to be the greatest health threat posed by ingestion of Radium (National Research Council,1988). The toxicity of uranium is also twofold: as a heavy metal, it may cause kidney damage ; and as a radionuclide, it may induce cancer.(National Research Council,1988).

Basically, the presence of radio nuclidesin drinking water results from one or more of the following sources:

1. Naturally occurring radioactive species e.g. radionuclides of the thorium and uranium decay series in drinking water sources, in particular, radium- 226/228;

2. Technological processes involving naturally occurring radioactive materials e.g., the mining and processing of mineral sands or phosphate fertilizer production and usage;

3. Radio nuclides discharged from nuclear fuel cycle facilities;

4. Manufactured radionuclides produced and used in unsealed form, which might enter drinking-water supplies as a result of regular discharges and, in particular, in case of improper medical or industrial use and disposal of radioactive materials. 


\subsection{Materials}

\section{Materials And Methods}

\subsubsection{The proportional counter}

The equipment used for the gross alpha and gross beta counting is a gas flow proportional counter, that is, desktop gross alpha/beta counter with dimensions $9 \frac{1}{4}$ "W X $11^{3} / 4$ " H X $16^{3} / 4$ " D; it is light weight,weighing less than 35Ibs with most options.It has easy sample loading,and multiple control options (keypad/console, programmable touch panel, standard pc).The detectors are gas flow proportional, ( 2 nos.), with full access maintenance(take the top off,and everything is accessible);low background readings (with optional shield $: 0.05 \mathrm{cpm}$ Alpha and $38 \mathrm{cpm}$, Beta); with window or windowless (i.e. highest alpha and beta efficiency field changeable)optionsThe counting gas is P-10 gas; and the system is connected direct to a printer i.e., a microprocessor IN-SYST; a spreadsheet programmeQuartro-PRO and a graphic programme MULTIPLAN (Akpa, et al 2004).

\subsubsection{Other materials}

Other materials used for the various experimental stages of this work include:twenty 2-litre plastic containers to collect the water samples; conductivity meter in order to measure the conductivity of the water samples; global positioning system(GPS) for acquiring accurate geographical co-ordinates of the wells and boreholes; stainless steel planchets; glass beakers; hot plate; weighing balance (accurate to $\pm 0.1 \mathrm{mg}$ ).Also, the following reagents were used:nitric acid, acetone and vinyl acetate.

\subsection{Methods}

The International Standard Organization procedure (ISO9696 and ISO9697:1992E) for the measurement of gross alpha and beta activities in water was employed in this analysis. This procedure provides a screening technique to determine the gross alpha and beta radioactivities in water samples. The procedure is highlighted below:

\subsubsection{Sampling Sites}

The area under study is the Kaduna North,Local Government area;and this investigation is limited to underground water sources (wells and boreholes) used by the people for drinking,domestic and other uses.Samples were collected at various locations in the local government area. This area is situated within Kaduna metropolis. The exact geographical locales will be determined by hand held GPS (Global positioning system) devices.

\subsubsection{Sample collection}

A total number of 20 samples were collected:the local government area was divided roughly into twenty sections, in order to obtain widely spread and representative samples.

\subsubsection{Preparation of samples}

Samples were collected in clean 2 litresplastic containers with tight covers. The volume of the sample collected was such that an air space of about $1 \%$ of the container was left for thermal expansion. To avoid contamination, the boreholes were allowed to run so as to evacuate the existing water in the pipe before collection. The containers were also rinsed thoroughly with water. The specific conductivity of the water was measured on collection, and the water samples were preserved with $20 \mathrm{ml}$ of concentrated $\mathrm{HNO}_{3}$ per liter of water in order to minimizeprecipitation,bacterial growths and absorption on container walls;also, in case there are chloride salts in the samples, the $\mathrm{HNO}_{3}$ will convert these salts to nitrate salts (chlorides will attack stainless steel and increase the sample solids, and no corrections can be made for those added solids).

\subsubsection{Determination of total solid}

The total solid concentration in the samples was determined in order know the appropriate volume of water to evaporate for each sample so as to avoid unnecessary sample thickness which may lead to selfabsorption. The volume of water required is such that it can produce a mass of solid residue slightly in excess of $0.1 \mathrm{Amg}$ (where $\mathrm{A}$ is the area of the planchet in $\mathrm{mm}^{2}$ ) Appropriate volume of the sample that can produce a mass of solid residue slightly in excess of $0.71 \mathrm{mg}$ was evaporated to near dryness using hot plates. The evaporation was done at a temperature less than $100^{\circ} \mathrm{C}$ until the volume was reduced and allowed to cool.It was then transferred to a glazed porcelain dish and evaporated to dryness under an infrared lamp. The residue was further heated for one hour at $120^{\circ} \mathrm{C}$ and allowed to cool in a dessicator.Aliquots were transferred toplanchets and evenly dispersed with a spatula,to which small quantities of acetone were added.Thisis in order to reduce moisture;too,a small amount of vinyl acetate was added, to further dry the samples on theplanchets.

The residues were taken for counting of gross alpha and beta activity using gas flow proportional counter. 


\subsubsection{Counting}

The counting equipment is automated. The procedure involves entering the preset time, number of cycles and the counting (operational) voltage. Also, the counter characteristics (efficiency and background count rate),volume of sample used and sampling efficiency were entered. The sampling efficiency was calculated as follows:

Sampling efficiency $=\left(\mathrm{W}_{\mathrm{B}+\mathrm{S}}-\mathrm{W}_{\mathrm{B}}\right) \times 100 \%$

$\mathrm{W}_{\mathrm{B}-\mathrm{S}}-\mathrm{W}_{\mathrm{B}}$

Where: $\mathrm{W}_{\mathrm{B}+\mathrm{S}}$ is weight of empty planchet plus sample after evaporation;

$\mathrm{W}_{\mathrm{B}}$ is weight of empty planchet;

$\mathrm{W}_{\mathrm{B}-\mathrm{S}}$ is weight of empty planchet - sample

Sampling efficiency $=$ Residue size obtained $\times 100 \%$

$$
\text { Required residue }
$$

Channel efficiency is given as:

$\mathrm{E}_{\mathrm{C}}=\frac{\operatorname{cpm}(\alpha, \mathrm{b}) \times 100 \%}{\mathrm{~A}}$

Where cpm $(\alpha, b)=$ background count per minute

$\mathrm{A}=$ activity of the source used (Pu-239 for alpha and $\mathrm{Sr}-90$ for beta).

\subsubsection{Expression of Results}

\section{(a) Gross alpha counting}

The high voltage for gross alpha counting was set at $1,600 \mathrm{~V}$, and samples were counted for 45 minutes in alpha only mode. Then the resultswere displayed as raw counts; (counts/minutes). The count rate and the activity were calculated using the formula:

Activity A $=$ Net count

D.E x sample volume xsaample efficiency x 60

Where D.E is the detector efficiency

Net count $=$ Raw count - Background count .

The reciprocal of 60 seconds is the conversion factor of activity toBq $/ \mathrm{m}^{3}$ fromcpm.

\section{(b) Gross Beta counting}

The high voltage for gross beta couting was set at $1,700 \mathrm{~V}$, and samples were counted for 45 minutes in beta only mode. The count rate and the activity were calculated using the formula:

ActivityB $=\quad$ Net Count

D.E x sample volume $\mathrm{x}$ sample efficiency x 60

Where D.E is the detector efficiency

Net count $=$ Raw count Background count.

The reciprocal of 60 seconds is the conversion factor of activity toBq $/ \mathrm{m}^{3}$ fromcpm.

\section{Results}

The Gas flow proportional counter used was initially calibrated using the manufacturer's Alpha and Beta sources ( $\mathrm{Pu}-239$ and $\mathrm{Sr}-90$ respectively) of known activities as at the time of calibration. The calibration is aimed at obtaining the operational efficiency of the channels of the counter after the calibration; the counter was then used to count the back ground radio activity of the environment. The gross alpha and beta radioactivity counting modes applicable to the counter, with respective voltages of 1,550 and 1,650 volts were then employed to count the prepared water samples collected from 20 different locations in Kaduna North Local Government Area of Kaduna State.

\subsection{Detector Calibration}

Plateau test was run with the manufacturers' calibration standards $(\mathrm{Pu}-239$ and $\mathrm{Sr}-90)$ whose activities range from $133.29-185.49 \mathrm{~Bq}$ and $92.31-103.68 \mathrm{~Bq}$ respectively in all the three operating modes. This test was run for 2700 s for 5 cycles. The operational efficiencies of the channels of the counter indicate an efficiency of $59.12 \%$ for the alpha counts and $44.0 \%$ for the beta counts. These are good efficiency values for this type of counting system.

\subsection{Background Radioactivity}

The counting system was then used to count clear empty planchets in all the counting modes to obtain the background radioactivity of the environment which is needed to be used in the subsequent measurements. The result gives background radioactivities of $92.69 \mathrm{cpm}$ for Alpha, and $95.65 \mathrm{cpm}$ for beta. This result is quite 
representative of the environment and could therefore be employed in the subsequent measurement of the water samples.

\subsection{Gross Alpha and Beta Radioactivity in Groundwater from various location in Kaduna North Local Government Area of Kaduna State}

Table 4.1 below shows the gross alpha and beta activity concentrations of the ground water of the selected locations in Kaduna North Local Government area, Kaduna State.

\begin{tabular}{|c|c|c|c|c|c|}
\hline \multicolumn{2}{|c|}{1111} & Geographical Coordinates & $\begin{array}{lllllllll}\text { L } & \text { o } & \text { c } & \text { a } & \text { t } & \text { i } & \text { o } & \text { n }\end{array}$ & \multicolumn{2}{|c|}{$\begin{array}{ll}\text { Activity } & \text { Concentration } \\
\times 10^{-3} \mathrm{~Bq} / \mathrm{L} & \\
\mathrm{ALPHA} & \text { BETA } \\
\end{array}$} \\
\hline & 1 & $\mathrm{~N} 10^{0} 31^{1} 17.8^{\prime \prime}: \mathrm{E} 007^{0} 27^{1} 45.3{ }^{\prime \prime}$ & HAMPOS SCHOOL & $6.39 \pm 2.38$ & $286.3 \pm 77.1$ \\
\hline ? & $\frac{T}{4}$ & $\mathrm{~N} 10^{0} 30^{1} 48.0^{\prime \prime}: \mathrm{E} 007^{0} 27^{1} 33.0$ & GOBARAU ROAD & $1.29 \pm 1.94$ & $822.6 \pm 92.5$ \\
\hline & i & $\mathrm{N} 10^{0} 33^{1} 11.9^{\prime \prime}: \mathrm{E} 007^{0} 27^{1} 48.3^{\prime \prime}$ & GWANI MUKTAR ROAD & $0.68 \pm 1.52$ & $491.1 \pm 84.2$ \\
\hline & $!$ & $\mathrm{N} 10^{\circ} 32^{1} 46.1^{\prime \prime}: \mathrm{E} 007^{0} 26^{1} 20.6$ & AP AKILU ROAD & $1.67 \pm 4.18$ & $1543 \pm 208$ \\
\hline & 3 & $\mathrm{~N} 10^{0} 31^{1} 53.3^{\prime \prime}: \mathrm{E} 007^{0} 27^{1} 57.9^{\prime \prime}$ & SHEHU LAMINU ROAD & $41.2 \pm 25.7$ & $9506 \pm 104$ \\
\hline & 7 & $\mathrm{~N} 10^{\circ} 29^{1} 54.4^{\prime \prime}: \mathrm{E} 007^{0} 26^{1} 24.7$ & B AKORI ROAD & $2.61 \pm 6.51$ & $2938 \pm 327$ \\
\hline 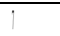 & & $\mathrm{N} 10^{0} 33^{1} 22.5^{\prime \prime}: \mathrm{E} 007^{0} 26^{1} 38.1$ & ZUNTU STREET & $15.01 \pm 6.00$ & $4836 \pm 209$ \\
\hline & 7 & $\mathrm{~N} 10^{0} 31^{1} 32.6^{\prime \prime}: \mathrm{E} 007^{0} 25^{1} 46.1$ & AHMADU BELLO STREET & $8.95 \pm 4.42$ & $537 \pm 160$ \\
\hline & 7 & $\mathrm{~N} 10^{\circ} 30^{1} 13.9^{\prime \prime}: \mathrm{E} 007^{0} 26^{1} 37.3$ & KABALA CUSTOMS OFFICE & $3.55 \pm 3.93$ & $991.6 \pm 174$ \\
\hline & 1 & $\mathrm{~N} 10^{0} 30^{1} 23.5^{\prime \prime}: \mathrm{E} 007^{0} 26^{1} 58.7^{\prime \prime}$ & G A M J I G A T E & $12.47 \pm 7.79$ & $1742 \pm 305$ \\
\hline & & $\mathrm{N} 10^{0} 33^{1} 21.8^{\prime \prime}: \mathrm{E} 007^{0} 27^{1} 18.7^{\prime \prime}$ & WURNO ROAD & $1.55 \pm 3.89$ & $1005 \pm 187$ \\
\hline & & $\mathrm{N} 10^{\circ} 31^{\mathrm{I}} 18.6^{\mathrm{\prime}}: \mathrm{E} 007^{0} 26^{\mathrm{I}} 58.7^{\prime}$ & TAFAWA BALEWA ROAD & $35.38 \pm 8.73$ & $899.7 \pm 233$ \\
\hline & & $\mathrm{N} 10^{0} 32^{1} 27.5^{\prime \prime}: \mathrm{E} 007^{0} 27151.3^{\prime \prime}$ & YAHYA ROAD & $8.52 \pm 5.32$ & $1067 \pm 207$ \\
\hline & 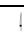 & $\mathrm{N} 10^{0} 30^{1} 17.4^{\prime \prime}: \mathrm{E} 007^{0} 26^{1} 48.9^{\prime \prime}$ & K U S E R O A D & $93 \pm 22.3$ & $5013 \pm 109$ \\
\hline & & $\mathrm{N} 10^{0} 30^{1} 38.6^{\prime \prime}: \mathrm{E} 007^{027} 1^{1} 16.6^{\prime \prime}$ & AL MANNAR MASJID & $7.38 \pm 4.00$ & $860.1 \pm 151$ \\
\hline 1 & 1 & $\mathrm{~N} 10^{0} 32^{1} 49.5^{\prime \prime}: \mathrm{E} 007^{0} 28^{1} 00.4^{\prime \prime}$ & DALEMA SUPER MARKET & $14.44 \pm 4.80$ & $9022 \pm 172$ \\
\hline & & $\mathrm{N} 10^{0} 32^{1} 55.6^{\prime \prime}: \mathrm{E} 007^{0} 26^{1} 48.6^{\prime \prime}$ & UNGUWAR SARKI & $19.66 \pm 12.3$ & $1300 \pm 554$ \\
\hline 1 & & $\mathrm{~N} 10^{0} 30^{1} 17.8^{\prime \prime}: \mathrm{E} 007^{0} 26^{1} 51.5$ & K U S E R O A D & $2.05 \pm 5.14$ & $7157 \pm 287$ \\
\hline & & $\mathrm{N} 10^{0} 32^{1} 27.4^{\prime \prime}: \mathrm{E} 007^{0} 27^{1} 51.3$ & YAHYA ROAD & $15.65 \pm 8.42$ & $8542 \pm 347$ \\
\hline$!$ & & $\mathrm{N} 10^{0} 33^{1} 22.5^{\prime \prime}: \mathrm{E} 007^{0} 26^{1} 38.0$ & ZANGO HOUSE & $14.10 \pm 5.54$ & $3458 \pm 204$ \\
\hline 2 & & & & & \\
\hline
\end{tabular}

Table 4.1 Gross Alpha and Beta Activity Concentration of Groundwater from various Locations in Kaduna North Local Government Area of Kaduna State.

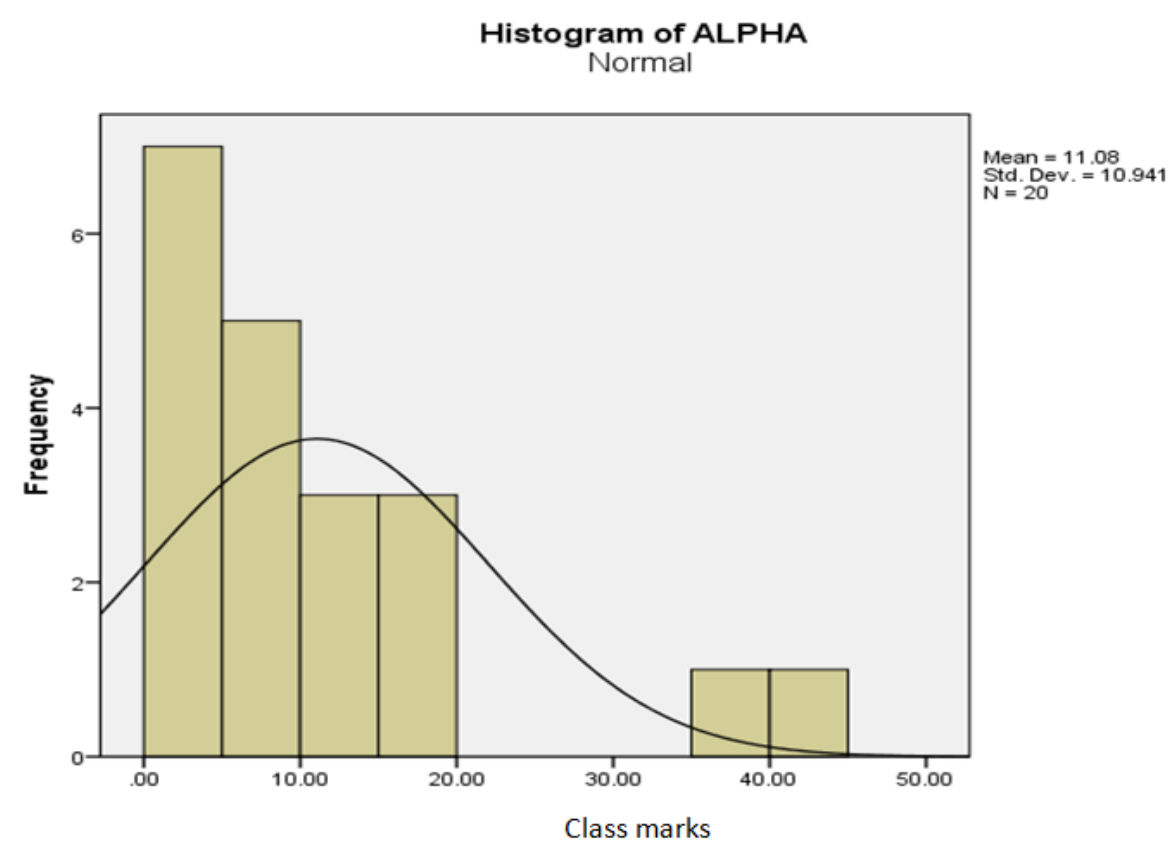

Fig 4.1:Histogram of alpha distribution

From figure 4.1 , it could be seen that the distribution of aalpha activities is skewed to the left.This means that most areas have low alpha activity.The regression curve represents a log-normal distribution, with a standard deviation, $\sigma=10.941$; a maximum theoretical frequency, $\mathrm{a}=6.75$. 


\section{Histogram of BETA}

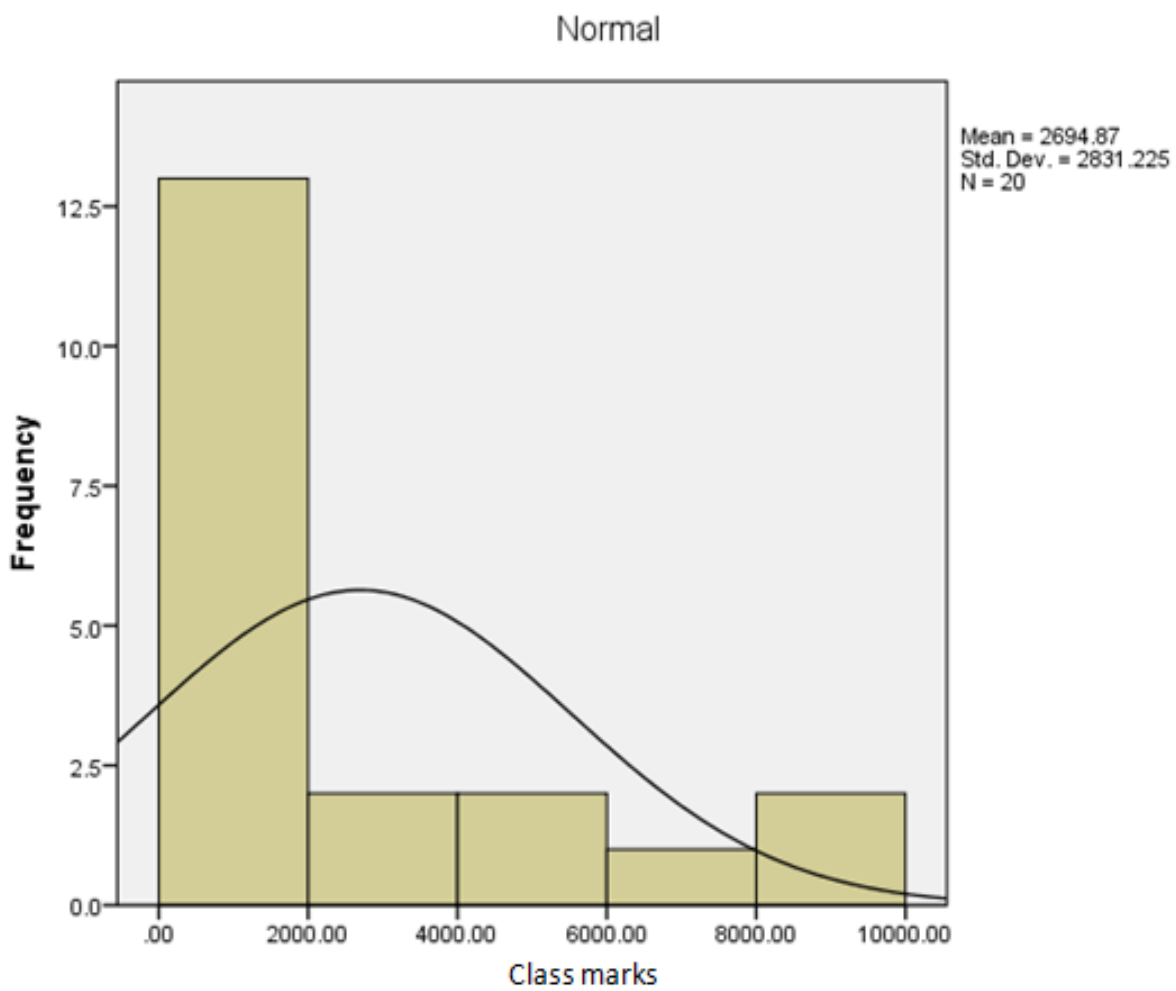

Fig 4.2:Histogram of beta distribution

From figure 4.2 above, it could be seen that the distribution of beta activities is only slightly skewed to the left.This means that most of the areas are of elevated activity, withsome quite highly elevated.The regression curve is a log normal distribution with a maximum theoretical frequency, $\mathrm{a}=13.15$ and a standard deviation, $\sigma=$ 2831.225 .

\section{Contour Graph Of Alpha Activity Density Distribution:}

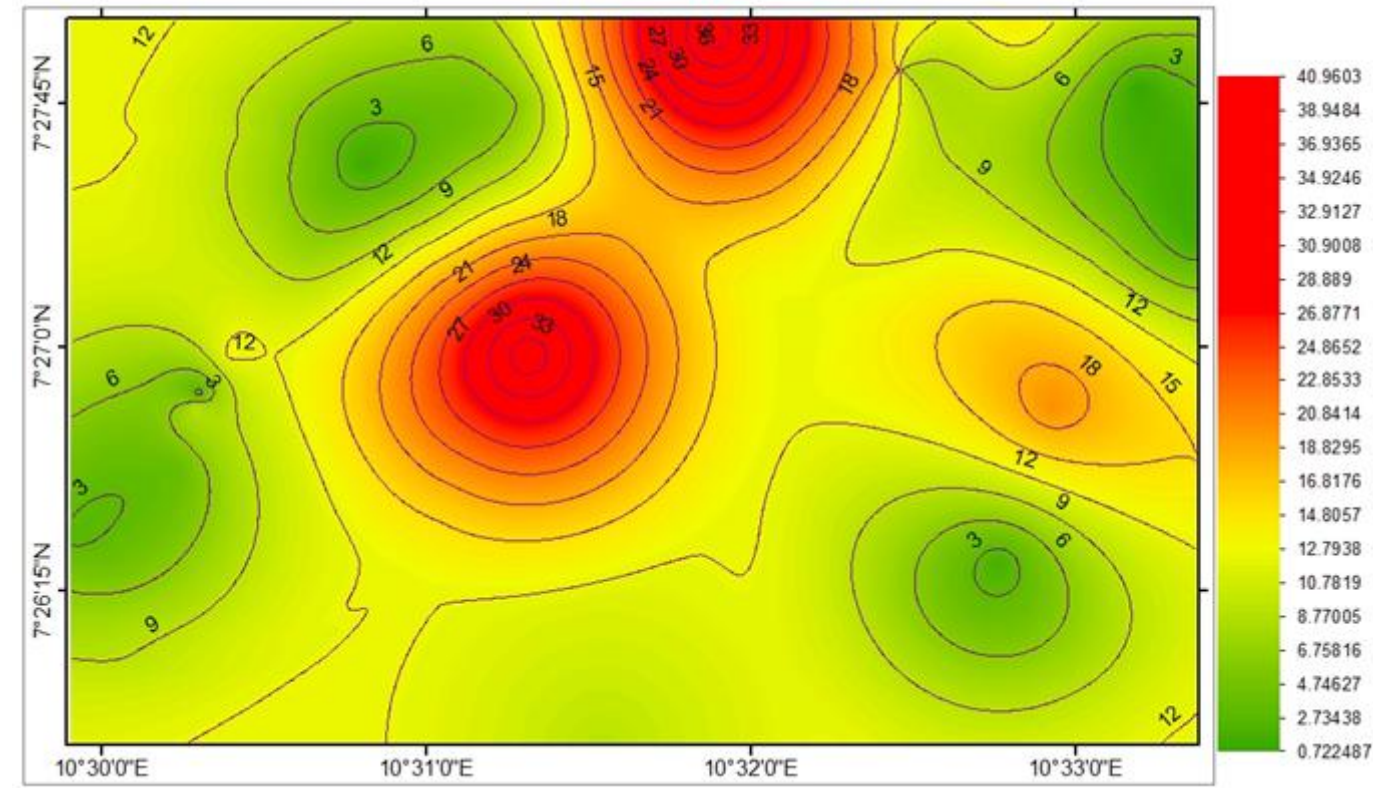

Fig 4.3:Contour distribution pattern of alpha activity

The contour map of figure 4.3 shows that there are slightly elevated areas of high alpha activity (though not above WHO mandated levels), bounded by longitude $10^{0} 31^{1}-10^{0} 32^{1} 55^{\prime \prime}$ and latitudes $7^{0} 26^{1} 34^{\prime \prime}-7^{0} 27^{1} 60^{\prime \prime}$ 


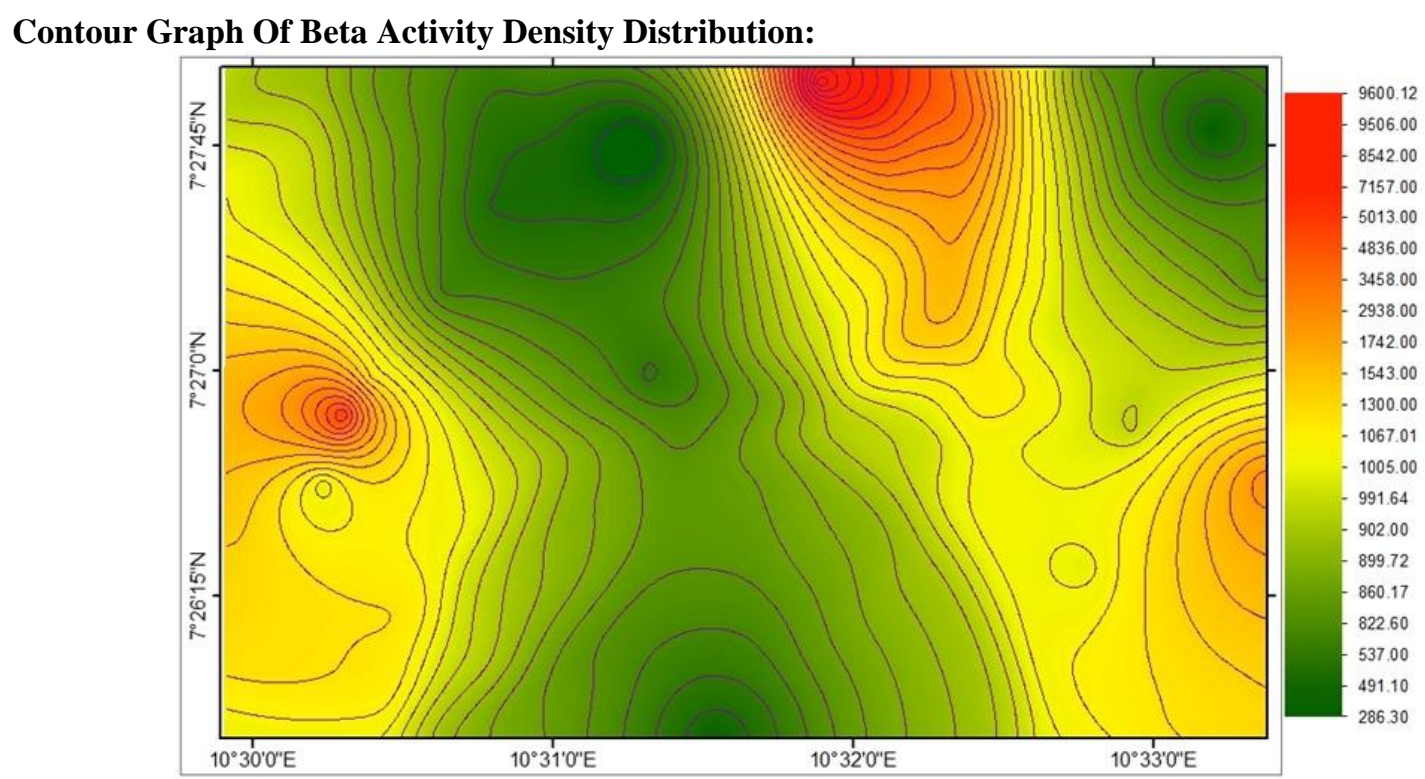

Fig 4.4:Contour distribution pattern of beta activity

Fgure 4.4 above (contour distribution pattern of beta activity),shows two widely separated areas of quite high beta activity.The areas are hehuLamiruroad,Yahyaroad,Bakoriroad,Zuntustreet,Unguwarsarkiroad,all in Unguwarsarkiward.Theother area of high elevated activity is Kuseroad,Gamjigate,Customsoffice,all of hooting range ward.

\subsection{Discussion}

\section{Discussions, Conclusion And Recommendations}

The gas flow proportional counter used for this analysis gave an average efficiency of $59.12 \%$ and 44 . $09 \%$ for the respective alpha and beta calibration sources. These are good values for this type of counter. A low background activity was also observed with a $92.69 \mathrm{cpm}$ for Alpha and $95.65 \mathrm{cpm}$ for Beta. This is quite representative of the environment. Similarly, the results obtained from all the counting modes are reproducible and are hence reliable. The Gross alpha and beta activity concentrations in the water samples were found to range from $(0.69 \pm 1.52) \times 10^{-3}$ to $(41.2 \pm 25.7) \times 10^{-3} \mathrm{~Bq} / \mathrm{L}$ :and from $(286 \pm 77.1) \times 10^{-3}$ to $(9506 \pm 104) \times 10^{-3} \mathrm{~Bq} / \mathrm{L}$ respectively.This indicate areas of alpha and beta activity concentrations, When compared with ICRP (1991) maximum acceptable values of $0.5 \mathrm{~Bq} / \mathrm{L}$ for alpha and $1 \mathrm{~Bq} / \mathrm{L}$ for beta and Radon-222, the beta radioactivities show highly elevatedvalues.

\section{Conclusion}

The gas proportional counter used for this research responded positively to the alpha and beta radioactivity, the counting modes employed gave alpha efficiencies of 59.12\% for alpha. Similarly the beta efficiency obtained is $44.09 \%$ for beta.

\section{Recommendation}

1. In light of the quite high levels of beta activities, further screening and radionuclide characterization of the ground waters of the area, as well as the assessment of all relevant radiological issues should be undertaken, in order to safeguard the members of the area from unwanted radiation exposure;

2. Radon Activity Concentration in the ground water in the area and its effect on the environment should be investigated, as it may also pose a potential health threat to the people;

3. The counting system should be upgraded with a higher version computer system for speedy processing of radioactivity measurement.

\section{References}

[1]. Agbalagba, et al (2012) Determination of Gross $\alpha$ and $\beta$ Activity Concentration and Estimation of Adults' and Infants' Dose Intakes in surface and Ground Water of Ten Oil Fields Environment in Western Niger Delta of Nigeria.

[2]. Alan, M. and Samuel, A. (1992).An introduction to Radiation. London, New York pp. 6 - 9

[3]. American Society for Testing and Measurements: standard test method for Randon in drinking Water.ASTM Designations: D507 98 pp. $67-69$.

[4]. Cember, H. (1996) Introduction to Health physics, $3^{\text {rd }}$ Edition Mcgraw Hill, Inc,.Toronto pp. 220 - 231

[5]. Cothern, CR. (1983) 'health effects Guidance for uranium in drinking water" Health physics 44 (377) 84. 
[6]. Eisenbud, M. and Panschoa, A.S. (1989).Environmental Radioactivity.

[7]. Helliwell, P.R (1975). Pollution criteria for Estuaries, Pentech Press London. Pp. 75 - 78.

[8]. ICPR (1979).Limits for Intakes of Radionuclides by Workers. International Commission on Radiological Protection.Pergamonpress ,newyork.277pp.

[9]. McCurry P. The Geology of the precambirian to lower paleozic rocks of Northern Nigeria. A review in Kogbe, C.A.(second edition),

[10]. Geology of Nigeria. Elizabelhen publication company, Lagos (1976), pp 13 - 37 Microsoft student Encarta: (2009ed.)

[11]. Milla, W.A. (1990), Risk Assessement and Control management of radon in Drinking water. In : (Conthern, C.R. and Rebers, P.eds) Radon, Radium andUrainium in Drinking water. Lewis publishers, Washington D.C PP. 27 - 37.

[12]. Milvy, P. and Cothern, C.R. (1990). 'Scientific Background for Development of Regulations for radionuclides in Drinking water'.'Lewis Publishers Washington DC. Pp. $1-14$.

[13]. Muhammad, B.G., M.S. Jaafar and T.C. Akpa, (2010). A survey of grossalpha and beta activity concentrations in groundwater from Katsina Area of Northern Nigeria. Radiat. Prot. Dosim., 142, 127 - 133.

[14]. Szabo, G. (1993). Water Quality Management.Public Health, 160 (4) 619 -648.

[15]. Turner, J.E. (1995). Atoms, Radiation and Radiation protection John Wiley and Sons inc.New York/ Chichester/Brisbane/ Toronto.

[16]. UNSCEAR. (1993) "Ionisation: Sources and effect of Ionization Radiation" Reports to the general Assembly, with Scientific annexes, United Nations sales publication E.94.IX.2.United Nations, Newyork USEPA report (2000) USNRC report (1999) Webb P.K. Recent research on the Geology between Zaria and Kaduna.

[17]. Savannah Vol. 1. No. 2 Yarar, Y and Kam, E. (2005) 'Environmental radioactivity concentration Of Tekirdag', International Cogress Series, Vol. 1276, p387 - 389. (49) 